\title{
Multi-temporal SAR and Optical Data Combination with Textural Measures for Land Cover Classification
}

\author{
土地被覆分類におけるテクスチャ計測を用いた \\ マルチテンポラル SAR と光学データの併用
}

Chureesampant KAMOLRATN and Junichi SUSAKI
チュリーサンパン カモンラット*・須㠃 純一*

\begin{abstract}
This paper proposes the classification framework based on the Bayesian theory with the single polarization multi-temporal synthetic aperture radar (SAR) and an optical data, and incorporates the proposed training sample selection (SS) methods. Within this framework, the combination with gray level co-occurrence matrix (GLCM)-based textural measures is investigated. The two procedures of the classification and proposed SS are united, where SS generates the accurate and dispersed training samples. Extracted features from multi-temporal SAR data-namely, the average backscattering coefficient, the backscatter temporal variability, and the long-term coherence and the reflectance values from optical data, are integrated with the GLCM textural data. Classification results were generated by taking Osaka City, Japan, as the study area. The selected major classes were water bodies, woodlands, fields, and built-up areas. The most suitable data used for classification was the multi-temporal SAR and an optical data combination with the mean textural, because of the supplement of different data and the smoothing effect of the texture. The higher quality training samples obtained by using the combined Support Vector Machine (SVM) and Neural Network (NN)-based SS method for training the Bayesian classifier generated the highest classification accuracies in all of tested cases.

和文概要：本論文では，トレーニングサンプル (SS) 選択方法を組み込みながら, 単一偏波の多時期 SAR と光学デー夕 をベイズ理論に基づいて統合して分類するフレームワークを提案する。このフレームワークでは，グレーレベル生起行列 (GLCM) ベースの平均值テクスチャを用いた組合せが検討されている。より正確で空間的に分散したトレーニングサンプ ルを生成する SS の処理と, 分類という 2 つの処理が統合されている。提案するフレームワークでは, 多時期の SAR デー 夕から抽出された特徵一平均後方散乱係数, 後方散乱の時間変動, 長期間のコヒーレンスーと, 光学データから抽出され た反射率が，GLCM の平均值テクスチャを経由して統合されている。大阪を対象地に選んで分類が行われた。選択した土 地被覆クラスは, 市街地，野原，森林，水域であった。最も分類に適したデー夕は，異なるデー夕の相互補完，テクスチャ の平滑化効果という点で, 多偏波 SAR と光学データを平均值テクスチャを経由して統合するものであった。サポートベク ターマシン（SVM）とニューラルネットワーク（NN）べースのSS 手法で改良されたトレーニングサンプルを用いて分 類した結果が，全てのケースの中で最も高い分類精度を示した。
\end{abstract}

\section{Introduction}

Remote sensed imagery can be acquired by microwave and optical sensors. In land cover classification, such optical images are easy to interpret, while images acquired by synthetic aperture radar (SAR) are difficult to interpret. However, utilizing SAR data has several advantages, for example, its qual-

*京都大学大学院工学研究科

「写真測量とリモートセンシング」VOL. 51，NO. 4， 2012 ity is unaffected by atmospheric and sunlight conditions. SAR also provides cloud-free images and also multi-temporal data. Hence, regions can be monitored at a time defined according to end-user requirements. The significant differences between these two imaging methods are due to the properties of their signals. SAR signals contain specific information about the sensitivity of the backscattering coefficient to the target geometry and permittivity, and the coherence of the electromagnetic pulse such that interferometry can be used (Oliver and Quegan, 1998). Conversely, information on the spectral re- 
flectance is contained in an optical sensor signal (Chander and Markham, 2003). However, there are some limitations in using SAR and optical data for classification, such as the geometrical features (i.e., foreshortening, layover, and radar shadow) and the presence of speckle noise in SAR images, while optical sensors often fail to acquire cloud-free data (Bruzzone et al., 2004). Considering these issues, obtaining high classification accuracy is difficult if only a single--source image or a single-polarization SAR image is used. Therefore, the multi-temporal SAR data and optical data integration can be considered as a viable operational tool for land cover classification. It is assumed that classification accuracy improves if additional features are incorporated; specifically, the greater the amount of included information, the higher the probability that interclass confusion will be reduced (Tso and Mather, 2011). This concept provides the impetus behind development of the multisource classification methodologies. In addition, the texture is considered as a significant parameter in the analysis of remotely sensed images for identifying land cover classes because it can describe the object surfaces. One way to derive the texture of an image is by using GrayLevel $\mathrm{Co}^{-}$occurrence Matrix (GLCM). GLCM is a tabulation of how often different combinations of pixel brightness values, or gray levels, occur within an image, and uses a series of second-order texture calculations (Haralick, 1979). The second-order measures consider the relations between pairs of neighboring pixels in the original image (Hall Beyer, 2007).

Since nonlinear features are extracted from the multi-temporal or fused images originating from different sources, the appropriate supervised classifiers should be considered for classification (Tso and Mather, 2011). Bayesian decision theory (supervised classification) is used to classify the land cover classes because it is the fundamental statistical approach for handling pattern recognition problem with an independent assumption (Duda et al., 2001). Although the supervised classifiers have shown great potential in the remote sensing field, their performance depends on the quality of the labeled data used in training. Generation of the training sets is typically performed by human experts, and thus is subject to errors and cost. The collection of the training samples is critical in the classification process (Tuia et al., 2009). Thus, the training sample selection (SS) is proposed to generate high quality of the training samples automatically to train a classifier. Several aspects of the SS method are considered including, selecting the accurate training samples, defining the appropriate number of the training samples in each class, and distributing the training samples. To fulfill all the above aspects, the procedure has the following three methods: (1) Support Vector Machine (SVM), a promising non-linear, non- ${ }^{-}$parametric classification technique, which provides a high accuracy of classification ( $\mathrm{Wu}$ et al., 2004). According to the literature, Neural Network (NN) has similar performance (Richards, 1999). The SVM and the NN classifiers are used to generate the pre-identified images, and then the ROI points are selected randomly on the pre-identified images. It can assure that the accurate training samples are collected precisely ; (2) the number of the training samples is defined based on proportional sampling method (i.e., the area ratio of each class is computed according to the estimation of class area in the pre-identified images) ; and (3) the information entropy and spatial dispersion quality constraints is performed, which is used to quantify the spatial distribution of ROI points. In this regard to step (1), the pre ${ }^{-}$ identified image of the integration of SVM and NN classifiers is expected to provide more accurate result than using individual SVM or individual NN classifier.

Hence, the main objective of this paper is the proposal of information fusion framework with the textural measures combination for classification and to tackle problems of the training sample selection and increase the quality of training samples. The proposed framework is based on Bayesian 
theory that incorporates the individual SVM ; individual $\mathrm{NN}$; or SVM and $\mathrm{NN}$-based SS methods. Accordingly, the classification capabilities of multi -temporal SAR and an optical data are investigated, both individually and in combination with GLCM-based textural measures (Hall-Beyer, 2007). The remainder of the paper is organized as follows. Section 2 introduces the characteristics of the study area. The classification framework is presented in Section 3, and the experimental results are reported and discussed in Section 4. Finally, the paper is concluded in Section 5.

\section{Study Area and Data Description}

Since the development of the information fusion classification framework is focused on a specific classification problem from the application viewpoint, therefore four- ${ }^{-}$class problem especially aimed to discriminate into water bodies, woodlands, fields, and built-up areas. An appropriate study area was selected in Osaka City, Japan (Figure 1). Fourteen level 1.1 PALSAR images with an ascending orbit of observation and $34.3^{\circ}$ off-nadir angles acquired between 8 October 2006 and 16 July 2009 were selected. The number of pixels for the images was $9,344 \times 18,432$ in fine-beam single-polarization (FBS) mode and 4,640 $\times 18,432$ in fine-beam double - polarization (FBD) mode. An optical AVNIR-2 image at level 1B2G (geometrically corrected data) with a descending orbit of observation acquired on 18 May 2009 was also selected. The size of the image was $8,491 \times 8,390$ pixels at a $10 \mathrm{~m}$ spatial resolution.

In Table 1, the training sets were selected based on a proportional sampling method where more sample pixels were selected for larger classes. To assess the classification accuracy, the test sets were

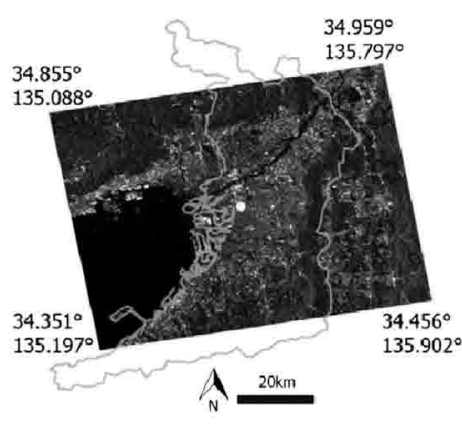

(a)

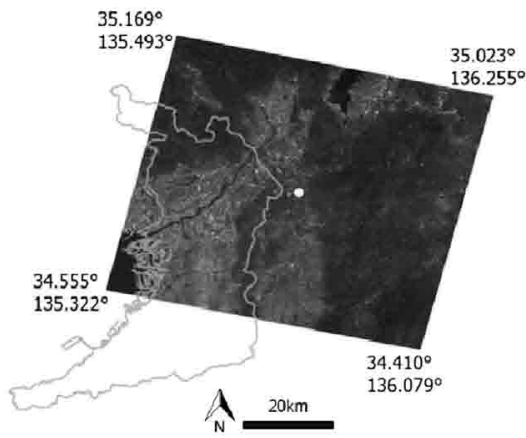

(b)

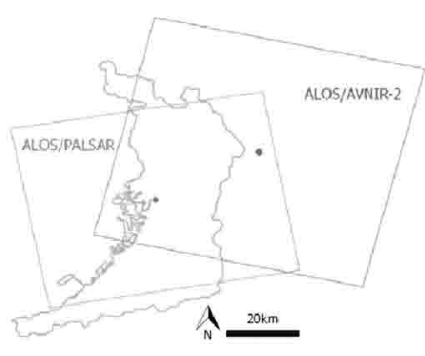

(c)

Figure 1 Study area and location of Osaka city, Japan. (a) L-band HH polarization ALOS/PALSAR image, acquired on 16 July 2009. (b) False color composite of ALOS/AVNIR-2 image, acquired on 18 May 2009. (c) Overlapping of PALSAR and AVNIR-2 images.

Table 1 Number of training and test sets used in the study

\begin{tabular}{|c|c|c|c|c|c|c|}
\hline \multirow{3}{*}{ Land cover class } & \multicolumn{5}{|c|}{ Training set (pixels) } & \multirow{3}{*}{ Test set (pixels) } \\
\hline & \multirow{2}{*}{ Original } & \multirow{2}{*}{ Suboptimal } & \multicolumn{3}{|c|}{ Training SS Methods } & \\
\hline & & & SVM & $\mathrm{NN}$ & SVM \& NN & \\
\hline Water & 1,893 & 201 & 1,527 & 1,520 & 1,611 & 18,108 \\
\hline Woodland & 7,779 & 208 & 8,181 & 7,394 & 9,750 & 77,181 \\
\hline Field & 4,325 & 212 & 5,360 & 3,924 & 3,445 & 42,857 \\
\hline Built-up & 8,259 & 212 & 8,670 & 9,686 & 8,664 & 80,660 \\
\hline Total pixels & 22,256 & 833 & 23,738 & 22,524 & 23,470 & 218,806 \\
\hline
\end{tabular}




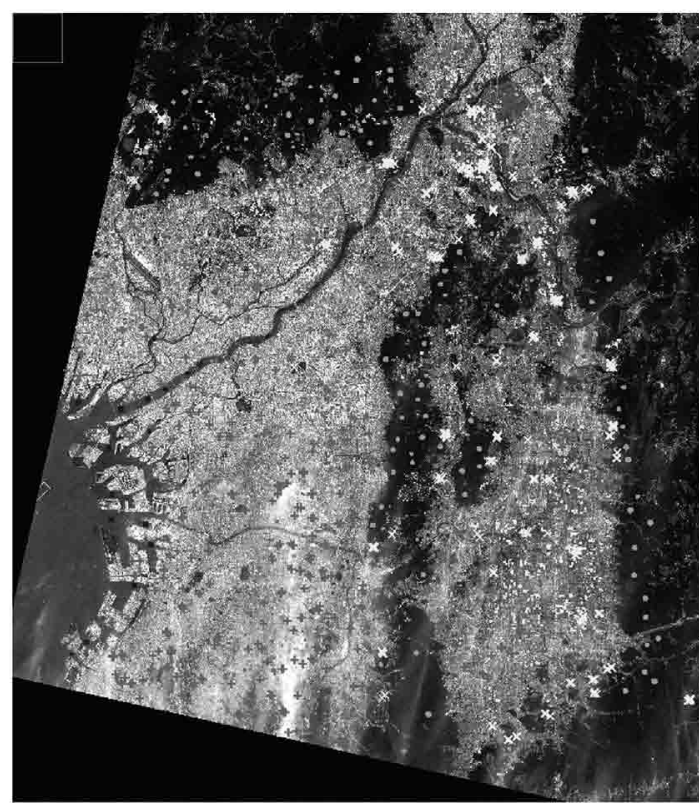

Water Woodland $X$ Field + Built-up

Figure 2 The test sets were selected by referring to the image on Google Earth and an AVNIR-2 image (blue: water class; green: woodland class; yellow : field class; and red: built-up class). selected from different sample ROIs than those used for the training sets. The test sets were also selected by referring to the image on Google Earth and an AVNIR-2 image, as shown in Figure 2.

\section{Information Fusion Classification Framework}

The proposed framework (Figure 3(a)) consists of the two major procedures, one is the classification procedure (Figure 3(b)), and another is the SVM or/ and NN-based SS methods for improving quality of the training sample sets (Figure $3(\mathrm{c})$ ), as delineated in Sections 3.1 and 3.2, respectively.

\subsection{Classification Procedure}

\subsubsection{Preprocessing and Processing Techniques}

PALSAR images were orthorectified to correct foreshortening by using a shuttle radar topographic mission (SRTM) $90 \mathrm{~m}$ digital elevation model (DEM). All images had to be preprocessed to obtain a consistent image size and geolocation. Since, the

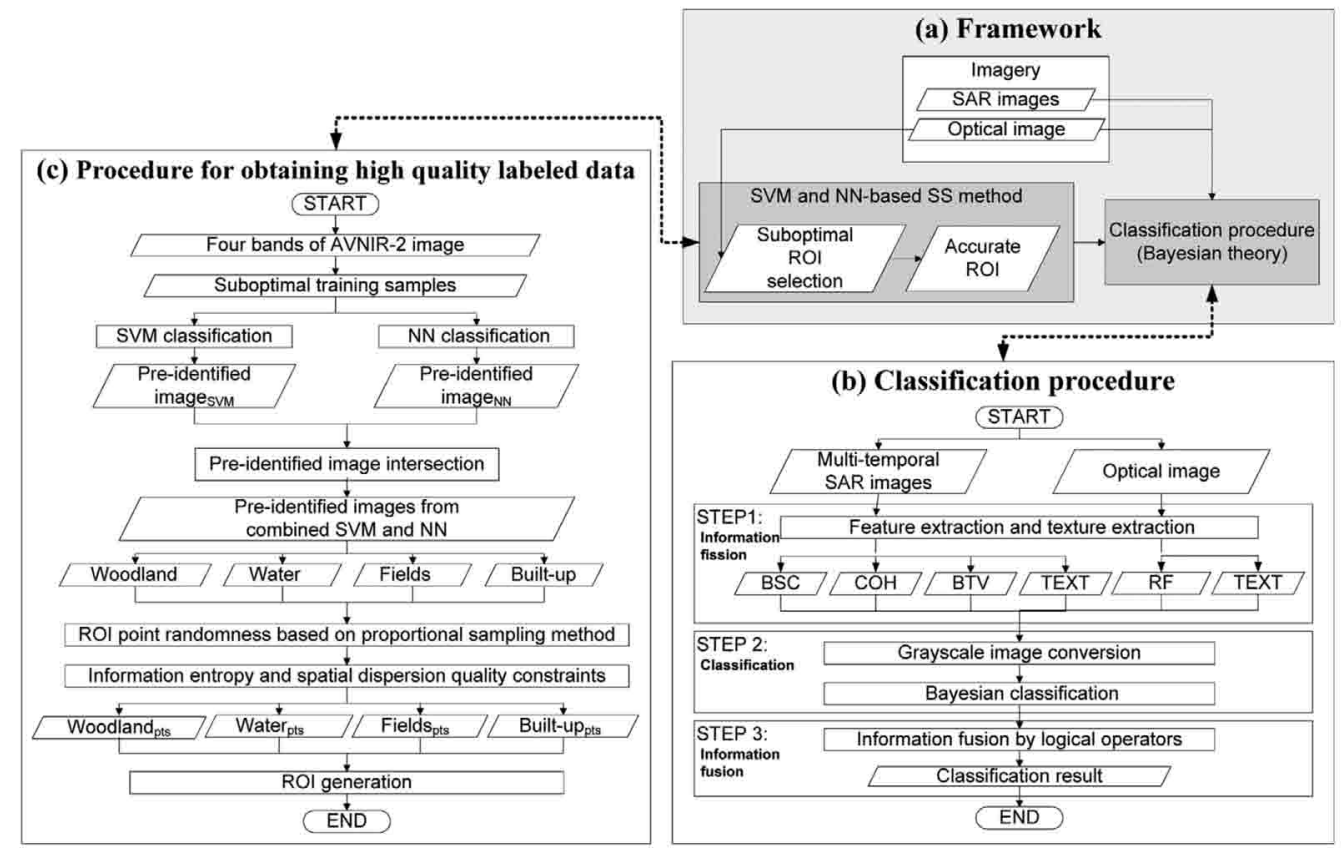

Figure 3 Framework overview. (a) Classification framework incorporates SS methods. (b) Classification procedure based on the Bayesian theory using multi-temporal SAR data and optical data combination. (c) Procedure for obtaining high quality labeled data from the SVM, the NN, and the combined SVM and NN-based SS methods. 
multi-temporal PALSAR images were obtained in both FBS and FBD modes, which have different range and azimuth resolutions (i.e., FBS mode has $9.4 \mathrm{~m}$ and $12.7 \mathrm{~m}$; and FBD mode has $4.7 \mathrm{~m}$ and 6.4 $\mathrm{m}$, respectively). An optical AVNIR-2 image with a $10 \mathrm{~m}$ spatial resolution was also analyzed. The typical resolutions of SAR and optical data should be the same before performing the information fusion. Thus, the resolution of multi-temporal SAR data was adjusted to the same size as an AVNIR-2 image. The SAR images were also co-registered to the universal transverse mercator (UTM) projection of grid zone 53 north, and the WGS 84 geodetic datum surface. Furthermore, all images were clipped to a size of $5,493 \times 6,292$ pixels. This classification framework can be applied with any areas whatever, flat terrain or fluctuated terrain because the pre-processing in particular orthorectificaiton was performed by using DEM. It can ensure that the distortions will be relieved.

\subsubsection{Information Fission (STEP 1)}

Information fission was performed by feature and texture extraction from each source. For multitemporal SAR data, the three features were extracted based on the scattering properties of multi-temporal SAR data reported by Bruzzone et al. (2004). The average backscattering coefficient (BSC), the backscattering temporal variability (BTV) in particular standard deviation and the long-term coherence $(\mathrm{COH})$ could then be generated. Since the multi -temporal images were used, an appropriate noise reduction technique should be implemented. Thus, the multi-temporal filtering approach in Eq. (1) was applied to remove noise (Quegan and Yu, 2001).

$\sigma_{f i l, i}^{0}=\frac{\sigma_{\text {forst }, i}}{M} \sum_{i=1}^{M} \frac{I_{i}}{\sigma_{i}}$.

Then, the filtered average backscattering coefficient is defined as:

$\sigma_{f i l, a v e}^{0}=\sum_{i=1}^{M} \frac{\sigma_{f i l, i}^{0}}{M}$.

where $I_{i}$ is the intensity values, $M$ is the number of images, $\sigma_{i}$ is the backscatter values, $\sigma_{f i l, i}$ is the filtered output for the $i^{\text {th }}$ input image, and $\sigma_{\text {forst }}$ is the Forst adaptive filtering of the backscattering coefficient image $i$.

In this research, the standard deviation was used because of its capabilities in identifying the spread of the backscattering coefficient. It is effective and its values are more meaningful and easier to understand. Therefore, the filtered standard deviation backscattering temporal variability is defined as :

stdev $=\sqrt{\frac{1}{M} \sum_{i=1}^{M} \sigma_{i}^{2}-\sigma_{\text {ave }}^{2} .}$

The coherence is defined as the absolute value of the normalized complex correlation coefficient (Cloude and Papathanassiou, 1998). The long-term L-band coherence was derived from tested multitemporal images and can be computed as follows. 1) Selecting several pairs of base and slave images ; 2) Generating the coherence images; and 3) Averaging those images.

Oliver and Quegan (1998) found out that the sufficient information for the discrimination of classes depends on the availability of information about the classes investigated and the number of temporal images considered. Accordingly, the backscattering coefficients, the backscattering temporal variability and the long-term coherence (computed on 14 images acquired 2-3 years apart) were derived. These features were considered in the view points of both the physics of the multi-temporal signals and their behavior in different land cover classes (Bruzzone et al., 2004). In addition, the spectral reflectance (RF) was calculated from the optical data and GLCM-based textural measures (TEXT) by HallBeyer (2007) were derived from both SAR and optical images. In total, seven textural measures were analyzed: mean, variance, correlation, contrast, homogeneity, dissimilarity, and entropy. Since small area was tested, the texture parameters to create the $\mathrm{co}^{-}$occurrence matrix were $3 \times 3$ window with horizontal and vertical directions that were shifted by 1 pixel. 


\subsubsection{Classification (STEP 2)}

In this research, the supervised classification was conducted with grayscale values (quantization phase) of the features from the information fission. Bayesian decision theory is then employed as the basis for classification (Tso and Mather, 2011). This theory is described by the probabilities. The posteriori probabilities are obtained for each of $c$ information class $\omega_{j}, j \in[1, c]$. These posteriori probabilities are further used in the classification process for assigning the label with the maximum a posteriori (MAP) estimation to each pixel of the data. The Bayesian probability theory states that:

$$
\begin{aligned}
& P\left(\omega_{j} \mid x_{1}, x_{2}, \ldots, x_{n}\right) \\
& \quad=\frac{P\left(\omega_{j}\right) \times P\left(x_{1} \mid \omega_{j}\right) \times P\left(x_{2} \mid \omega_{j}\right) \times \ldots \times P\left(x_{n} \mid \omega_{j}\right)}{P\left(x_{1}, x_{2}, \ldots, x_{n}\right)} .
\end{aligned}
$$

where $P\left(\omega_{j} \mid x_{1}, x_{2}, \ldots, x_{n}\right)$ is known as the posterior probability that $\omega_{j}$ is the correct class, given the observed data vector $\left(x_{1}, x_{2}, \ldots, x_{n}\right) . P\left(x_{1}, x_{2}, \ldots\right.$, $\left.x_{n} \mid \omega_{j}\right)$ is the likelihood probability. The prior probably of class $\omega_{j}$ is denoted by $P\left(\omega_{j}\right)$.

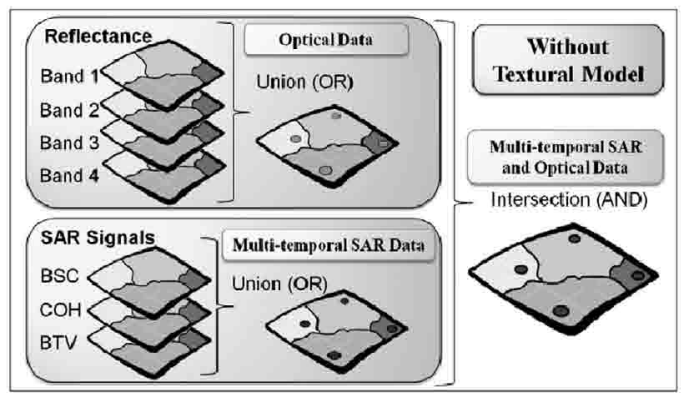

(a) Without textural model.

\subsubsection{Information Fusion (STEP 3)}

The AND and OR logical operators were applied to compute the final combined membership value to derive the final classification results. Figure 4 shows the three information fusion models, which are categorized based on textural measures namely, without textural model, with mean textural model and with all textural model.

(a) Information fusion without textural model is shown in Figure 4(a). The OR operator was applied for the cases of optical data (the combination of four spectral bands reflectance) classification or the multi-temporal SAR data (the combination of the three SAR signals) classification. To generate the classification results from the multi-temporal SAR and optical data combination, AND operator was used to fuse two first results above.

(b) Information fusion with mean textural model is illustrated in Figure 4(b). It shows the similar information fusion steps as without textural model. Mean textural is involved, therefore the original reflectance images or the SAR signals images are

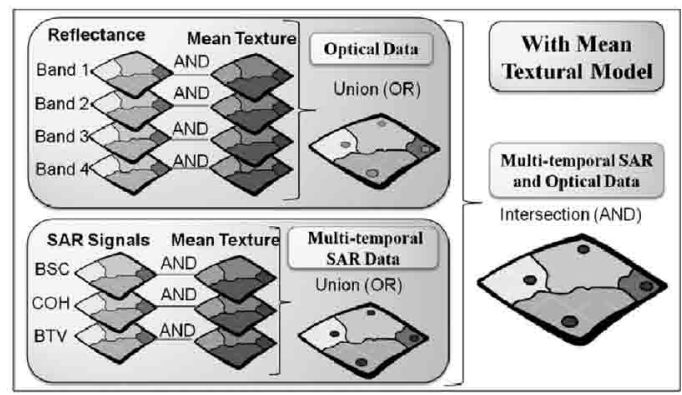

(b) With mean textural model.

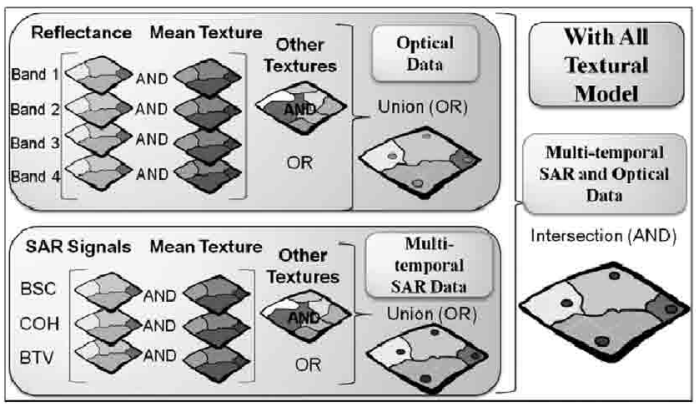

(c) With all textural model.

Figure 4 Three models of the information fusion. 
interested with their mean textural images by using AND operator initially.

(c) Information fusion with all textural model is shown in Figure 4(c). This model is similar to the information fusion with mean textural model. Firstly, the pairs of original features and their mean textural images were intersected by using AND operator, the additional steps about other six textural measures was involved. All other six textural measures of original reflectance of each band were intersected by using AND operator. Then, OR operator was used to unify with the results from mean texture combination.

\subsection{Training Sample Selection (SS) Methods Incor- porate SVM, NN and Combined SVM and NN}

\subsubsection{Suboptimal Training Sample Selection}

In Table 1, approximately 200 pixels in each class of the suboptimal training samples (column: Suboptimal) were selected from the original training samples (column: Original). To ensure the accurate suboptimal training samples can be obtained, they were also examined by photo interpretation of image on Google Earth and an AVNIR-2 image.

\subsubsection{Pre-identified Image Generation}

The suboptimal training samples were trained into two classifiers by employing the SVM or/and NN with the four bands of an AVNIR-2 image. Then, the SMV pre-identified image (pre-identified image $_{\text {SvM }}$ ) and the NN pre-identified image (pre-

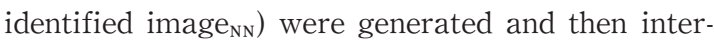
sected to produce the combined SVM and NN preidentified image (pre-identified image combined svm $\& \mathrm{NN})$. This process was conducted by using the commercial remote sensing package ITT ENVI version 4.4 (ITT, 2009), which provides the supervised support vector machine and the supervised neural network classifications. The SVM parameters used for this analysis were set as follows. The "Kernel Type" was Radial Basis Function (RBF), which works well in most cases. The "Gamma in Kernel Function", or the gamma parameter used in the kernel function, was 0.25 . This value is the inverse of the number of bands in the input image. The NN parameters used for this analysis were set as follows. The "Training Threshold Contribution" was 0.9 , the "Training Rate" was 0.2 , and the "Training Momentum" was 0.9. The "Training RMS Exit Criteria", or the RMS error value at which the training should stop, was 0.1 .

\subsubsection{ROI Generation}

At this stage, three pre-identified images were used to conduct three different SS methods (i.e., the SVM-based SS, the NN-based SS, and the combined SVM\&NN-based SS methods). The generated ROIs from each method were produced in the similar way, exception of the different pre $^{-}$ identified images were used. The performances of three SS methods were compared. This procedure was done without human intervention including: (1) the ROI point was randomly selected under each pre -identified image; (2) the spatial dispersion quality constraint was used to qualify the distribution of ROI points; and (3) the accurate and distributed ROIs were then generated with the less processing time. The steps are described below.

1) The area of each class in the pre-identified image was calculated as the number of pixels. Based on a proportional sampling method, the ratio of each class was computed by dividing the total area of the image.

2) In order to compare the classification performance before and after applying three SS methods reasonably, the number of pixels using for SS methods should similar to the number of original manual training samples pixels (column: Original in Table 1). Hence, the empirical weight was set to 15,000 and multiplied with the ratio of each area class calculated from no. (1) to estimate the number of pixels of ROIs. Since, a ROI was represented as $9 \times 9$ pixel rectangles (i.e., 81 pixels), the number of ROIs in each class can be calculated approximately.

3) However, ROI increment step was necessary since inappropriate ROIs will be removed during the 
process such that the number of ROIs is reduced. These inappropriate cases were $35 \%-45 \%$ of ROI points selected in non-overlapping areas of the optical and SAR data because the ROI point randomness was worked on an optical (AVNIR-2) image; or $16.67 \%$ of those failing to meet the applied information entropy and spatial dispersion quality constraints. Therefore, in the first and second steps of incrementing the ROIs, the original number of ROIs was increased by $40 \%$ and $20 \%$, respectively, to compensate for these reductions in the number of ROI points. The number of ROI points after the first step was used as a threshold for defining the minimum of number of ROIs when applying the spatial dispersion constraint, and the number of ROIs after second step were used to define the number of ROI point randomness. These percentage criteria of ROI increment steps can be adjusted as appropriate in each case.

5) To quantify the spatial distribution of ROI points, the information entropy of local regions and the spatial dispersion quality were utilized (Cheng et al., 2008). This can be used to reduce the useless ROI points, thus ensuring that the minimum number of ROI points can be obtained.

6) The ROIs were generated by creating $9 \times 9$ pixel rectangles with an ROI point at the center of each rectangle. Thus, the accurate and dispersed ROIs for the SVM, the NN, and the combined SVM and NN-based SS methods can be used to train the Bayesian theory classifier, as shown in Table 1 (column: Training SS method).

\section{Experimental Results and Discussion}

The proposed framework (Figure 3) was applied to Osaka City dataset. The images were classified by using multi-temporal SAR data, and combination of multi-temporal SAR and an optical data, with non-SS and SS methods individually. The

Table 2 Overall accuracies and kappa coefficient before and after applying SVM or/and NN-based SS methods

\begin{tabular}{|c|c|c|c|c|c|c|c|c|c|c|c|c|c|c|}
\hline \multirow{3}{*}{\multicolumn{3}{|c|}{ Information fusion cases }} & \multirow{4}{*}{$\begin{array}{l}\text { No. of } \\
\text { features } \\
3\end{array}$} & \multirow{2}{*}{\multicolumn{2}{|c|}{ Non-SS }} & \multicolumn{6}{|c|}{ Training SS methods } & \multicolumn{3}{|c|}{ OAdifference $^{c}(\%)$} \\
\hline & & & & & & \multicolumn{2}{|c|}{ SVM } & \multicolumn{2}{|c|}{$\mathrm{NN}$} & \multicolumn{2}{|c|}{$\begin{array}{c}\text { Combined } \\
\text { SVM \& NN }\end{array}$} & \multirow{2}{*}{ SVM } & \multirow{2}{*}{ NN } & \multirow{2}{*}{$\begin{array}{l}\text { SVM } \\
\& N N\end{array}$} \\
\hline & & & & $\mathrm{OA}^{\mathrm{a}}$ & $\mathrm{Kp}^{\mathrm{b}}$ & $\mathrm{OA}^{\mathrm{a}}$ & $\mathrm{Kp}^{\mathrm{b}}$ & $\mathrm{OA}^{\mathrm{a}}$ & $\mathrm{Kp}^{\mathrm{b}}$ & $\mathrm{OA}^{\mathrm{a}}$ & $\mathrm{Kp}^{\mathrm{b}}$ & & & \\
\hline \multirow{4}{*}{$\begin{array}{l}\text { 1. Multi-temporal } \\
\text { SAR }\end{array}$} & 1.1 & SAR signals & & 75.9 & 0.651 & 75.4 & 0.642 & 72.6 & 0.610 & 76.6 & 0.666 & -0.6 & -4.5 & 0.9 \\
\hline & 1.2 & Mean of SAR signals & 3 & 77.1 & 0.681 & 75.5 & 0.646 & 74.1 & 0.634 & 78.9 & 0.704 & -2.2 & -4.0 & 2.3 \\
\hline & 1.3 & SAR signals + Mean & 6 & 77.2 & 0.682 & 75.9 & 0.653 & 74.4 & 0.637 & 79.5 & 0.716 & -1.8 & -3.8 & 2.8 \\
\hline & 1.4 & SAR signals $+{ }^{d}$ All & 21 & 77.2 & 0.682 & & & & & & & & & \\
\hline \multirow{4}{*}{$\begin{array}{l}\text { 2. Multi-temporal } \\
\text { SAR and opti- } \\
\text { cal }\end{array}$} & 2.1 & $\begin{array}{l}\text { Reflectance and SAR sig- } \\
\text { nals }\end{array}$ & 7 & 79.3 & 0.718 & 86.6 & 0.798 & 83.9 & 0.761 & 90.8 & 0.866 & 8.4 & 5.4 & 12.6 \\
\hline & 2.2 & $\begin{array}{l}\text { Mean of reflectance and } \\
\text { Mean of SAR signals }\end{array}$ & 7 & 81.5 & 0.749 & 87.0 & 0.803 & 85.6 & 0.784 & 90.9 & 0.868 & 6.3 & 4.8 & 10.3 \\
\hline & 2.3 & $\begin{array}{l}\text { Reflectance }+ \text { Mean and } \\
\text { SAR signals }+ \text { Mean }\end{array}$ & 14 & 82.5 & 0.758 & 87.9 & 0.816 & 86.1 & 0.790 & 91.0 & 0.871 & 6.2 & 4.2 & 9.4 \\
\hline & 2.4 & $\begin{array}{l}\text { Reflectance }+{ }^{d} \text { All } \\
\text { SAR signals }+{ }^{d} \text { All }\end{array}$ & 49 & 84.9 & 0.792 & & & & & & & & & \\
\hline \multirow{4}{*}{ 3. Optical data } & 3.1 & Reflectance & 4 & 69.4 & 0.555 & 78.7 & 0.704 & 76.9 & 0.677 & 79.7 & 0.717 & 11.8 & 9.7 & 12.8 \\
\hline & 3.2 & Mean of reflectance & 4 & 75.5 & 0.647 & 82.1 & 0.746 & 78.0 & 0.692 & 86.0 & 0.803 & 8.1 & 3.3 & 12.3 \\
\hline & 3.3 & Reflectance + Mean & 8 & 76.2 & 0.657 & 83.4 & 0.763 & 81.7 & 0.740 & 86.5 & 0.809 & 8.7 & 6.8 & 11.9 \\
\hline & 3.4 & Reflectance $+{ }^{\mathrm{d}}$ All & 28 & 76.3 & 0.658 & & & & & & & & & \\
\hline
\end{tabular}

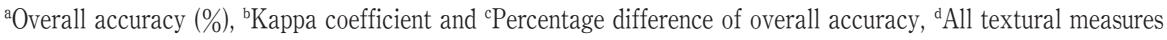




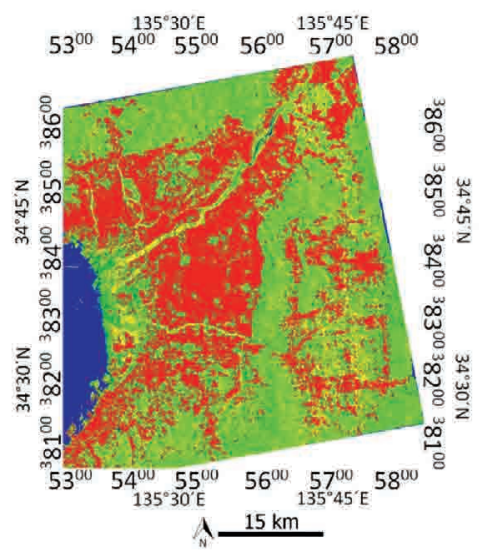

(a) SAR signals + All Textures.

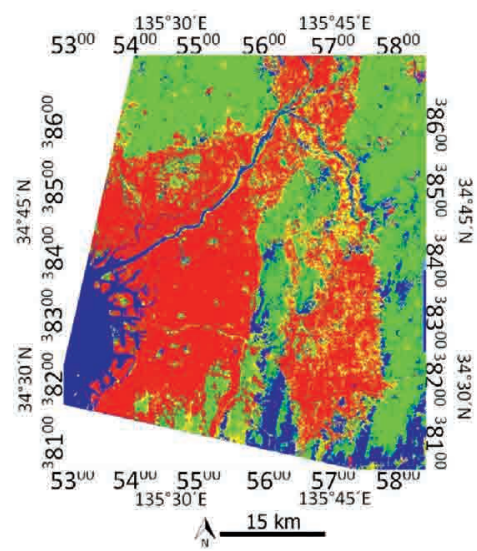

(b) Reflectance \& SAR signals + All Textures

$\square$ Water

$\square$ Woodland

$\square$ Field

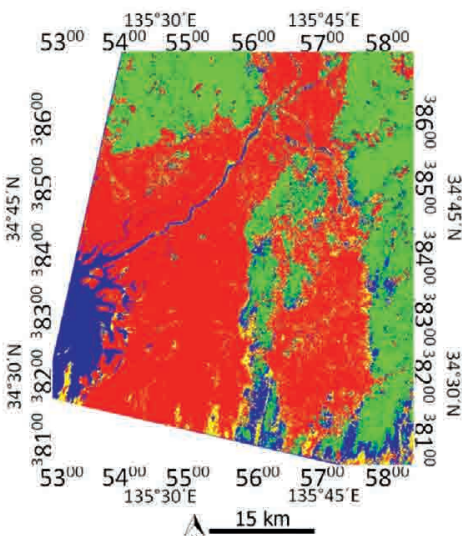

(c) Reflectance + All Textures.

Figure 5 Classification results combined with all textural measures. (a) Multi-temporal SAR data. (b) Multi-temporal SAR and an optical data combination. (c) Optical data.

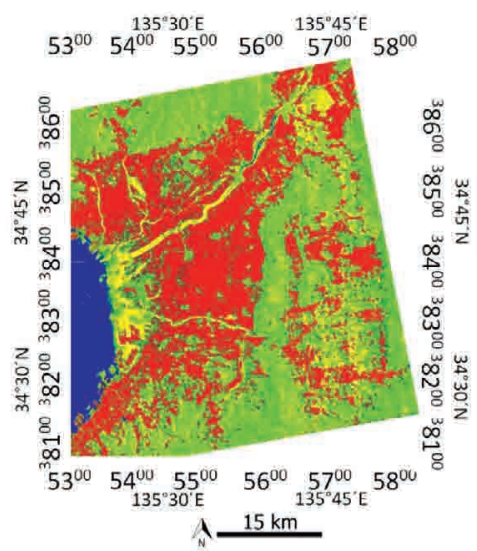

(a) SAR signals + Mean.

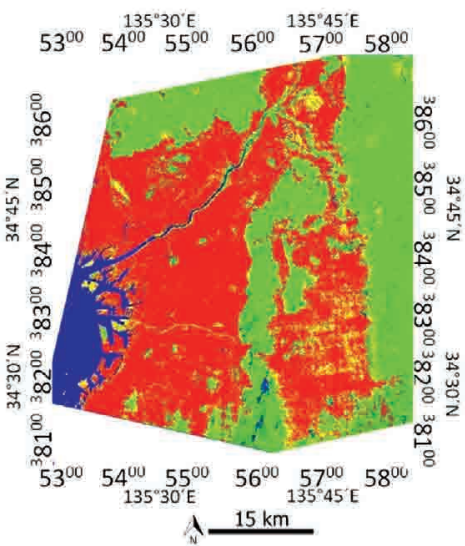

(b) Reflectance \& SAR + Mean

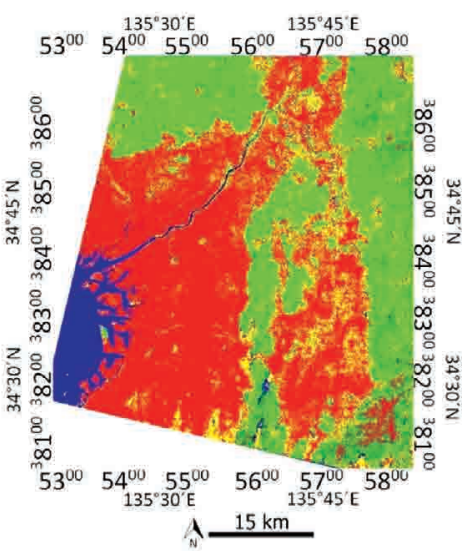

(c) Reflectance + Mean.

$\square$ Water

Figure 6 Classification results combined with the mean textural measure applying SVM and NN-based SS method. (a) Multi-temporal SAR data. (b) Multi-temporal SAR and an optical data combination. (c) Optical data.

results are shown in Table 2 and Figures 5 and 6.

\subsection{Multi-temporal SAR Data (with Non-SS)}

The classification results obtained from multitemporal SAR data in Table 2 (Case 1) are discussed as follows. Table 2, Case 1.1 shows the classification accuracy of three SAR signals combination including (the average backscattering coefficient, the backscattering temporal variability and the longterm coherence). The overall accuracy was $75.9 \%$. It can be found that the integration of the feature extraction approaches based on the physics of multi -temporal SAR signals can solve a multi-class problem. The $77.1 \%$ of overall accuracy of the mean texture of the three SAR signals combination is shown in Case 1.2, the result shows $1.6 \%$ improvement than the Case 1.1. In this regard, the percentage difference can be calculated as:

PercentageDifference $=100-\left(\frac{a}{b} * 100\right)$.

where $a$ is the lower number and $b$ is the higher number. 
As a result, mean texture can be used to improve the classification accuracy for SAR data, because it can reduce speckle noise most effectively. The combination of the original SAR signals and the mean texture (Case 1.3) gave the improvement in accuracy of only about $0.2 \%$. In Case 1.4 with Figure 5(a), the data combination of SAR signals and all texture of each signals, outperformed with the $0.1 \%$ increased accuracy (overall accuracy : 77.2\%).

\subsection{Multi-temporal SAR Data and an Optical Data (with Non-SS)}

The results from multi-temporal SAR data in Section 4.1 show low classification accuracies. Therefore, an optical data was considered to analyze. In this section, the classification results obtained from multi-temporal SAR data and an optical data combination in Table 2 (Case 2) with Figure 5(b) is delineated as follows. Table 2, Case 2.1 shows classification accuracy of the combination of the three SAR signals and the reflectance of four bands. The overall accuracy was 79.3\%. The combination of the mean texture of the three SAR signals is shown in Case 2.2. It was $81.5 \%$ overall accuracy, that is improved by $2.7 \%$ with respect to Case 2.1 . In Case 2.3, the accuracy of four bands of the reflectance and the three SAR signals with their mean texture combinations generated $82.5 \%$. Finally, in Case 2.4 with Figure 5(b), the combination of SAR signals and reflectance with all texture of each signals, outperformed the Case 2.3 with $2.9 \%$ (overall accuracy : $84.9 \%$ ).

It can be seen that the classification accuracies of using multi-temporal SAR and an optical data combination generated better accuracies than using only multi-temporal SAR data. In order to compare those two results above reasonably, the classification of optical data is also experimented as shown in Table 2 (Case 3). The lowest overall accuracy $(69.4 \%)$ of four bands reflectance was generated in Case 3.1. When the mean texture of reflectance of all four band combination (Case 3.2) was analyzed, it showed an $8 \%$ improvement over the original reflectance. The mean texture is established as a significant parameter for accurate classification. By contrast, the combination of the original reflectance and the mean texture (Case 3.3) gave a further improvement in accuracy of only about $0.9 \%$. And the accuracy of combination of original reflectance with all textural measures (Case 3.4 ) shows slightly increase (overall accuracy : 76.3\%), as illustrated in Figure 5(c).

From the classification results of multi-temporal SAR data (Case 1), multi-temporal SAR and optical data combination (Case 2), and optical data (Case 3) that incorporate with the mean textural measure were found to have great influence to improve the quality of classifications. The highest accuracies can be produced when all textural measures are combined in the three cases, with less than $2.9 \%$ improvement. Comparing the results for Case 2.4 with those for Cases 1.4 and 3.4, the classification accuracy was $9.0 \%$ and $10.2 \%$ higher respectively, which indicates that the multisource classification notably outperformed the single-source classifications. Moreover, the classification results of the combination of multi-temporal SAR data and optical data (Case 2.4, Figure 5(b)) showed a significant improvement in the previous two results. The drawbacks found in both the multi-temporal SAR data (e.g., layover and radar shadow phenomena causing the woodland class not to appear as a homogeneous area) and the optical data (e.g., the disappearance of the field class) were corrected by the complement from the combination of Cases 1 and 3. Moreover, the water class was clearly distinguished, for instance, Osaka Bay and the rivers that extend outward from the bay and along the field areas. However, certain woodlands areas were still incorrectly classified due to cloud cover in the optical data, such as the bottom-center area of the image. Therefore, the additions of the SS methods are considered next. 


\subsection{Multi-temporal SAR Data and an Optical Data (with SS Methods)}

The three training SS methods were applied to the data used in the previous section. The numbers of used features for information fusion classification were considered, as shown in Table 2 (column : Number of features). Comparing the number of used features between all textural model and mean textural model with the accuracy improvement, multitemporal SAR data (Case 1) has 6 and 21 features; multi-temporal SAR and an optical data (Case 2) has 14 and 49 features; and optical data (Case 3) has 8 and 28 features, respectively. These features of all textural model were used at more than 3.5 times the combination of mean textural model. When considering the performance comparison, a little improvement in accuracies was found for combinations with all texture images over combinations with mean texture images alone (i.e., the percentage differences are only $0.05 \%, 2.83 \%$, and $0.13 \%$ for Cases 1 to 3 , respectively). In this regard, the combination of mean texture case is preferable if all texture combination case is unavailable. Then, only the mean texture combination was used for testing. Following cases were studied in this section: (1) only optical data combining the reflectance of the four spectral bands or only multi-temporal SAR data combining the SAR signals; (2) GLCM mean texture of reflectance or SAR signals combinations; and (3) combination of reflectance and SAR signals and their mean textures. In this manner, the number of extracted features used and model complexity can be reduced.

The classification accuracies and results of three data cases from applying the combined SVM and NN-based SS method are shown in Table 2 (column : Training SS methods (combined SVM \& NN)) and Figures 6(a), (b), and (c), respectively. Let us consider the results, particularly in Table 2 (column: OA difference (combined SVM and NN)). These percentage differences were computed from Eq. (5). For all sub-cases of the multi-temporal SAR data (Case 1), accuracies were increased by less than
$3 \%$ with the addition of SS. While comparing the classification results for the SAR signals and mean texture combination (Figure 6(a)) with the SAR signals and all textural measures combination (non -SS) in Figure 5(a), Figure 6(a) shows the improvement in classification, because the woodland class appears to have greater homogeneity. Next, all sub -cases of multi-temporal SAR and optical data combination for Case 2 show the incremental improvements of around $9 \%-12 \%$. The reflectance, SAR signals, and their mean texture combinations in Case 2.3 generated the highest classification accuracy (91.0\%). Hence, the result for this case (Figure 6(b)) also shows the improvement over Case 2.4 without SS in Figure 5(b). The noises in woodland and built-up classes in Figure 6(c) were reduced, and the areas appeared homogenous. Lastly, in all sub-cases of optical data combination in Case 3 , accuracies were increased by around $11 \%-$ $12 \%$. The classification result for the combined reflectance and mean texture images (Figure 6(c)) shows improvement over the case with all textural measures and without SS (Figure 5(c)). Correction of the misclassification of the woodland class as the water class due to cloud cover is evident in the bottom-center of the image. Although this misclassification was not corrected perfectly, the higher quality of the labeled data for training the classifier is shown to be effective in solving this type of problem. From the comparison of the improvement percentage of three major data cases, it was found that the improving range for multi-temporal SAR data was the shortest. This mainly depends on the characteristics of the data used. The speckle noise in SAR data influences to a little improvement. As a result, an optical data significantly increased the accuracy (i.e., the largest range of accuracy improvement was generated). This was because the advantage of optical data makes it easy to classify and the SS methods assist to reduce the confusion between classes for the classification. The lower range improvement in the case of multi-temporal SAR and an optical data was attributed to the 
influence of speckle noise in SAR data.

Comparison of the classification performance from applying the individual SVM and individual NN-based SS methods is discussed. The tendency of the classification accuracies generated from the SVM-based SS method was similar to the $\mathrm{NN}^{-}$ based SS method. The classification accuracies of all cases after applying the NN-based method were lower than applying the SVM-based SS method. These results were shown in the percentage difference of overall accuracy (OA) column in Table 2, particular in the columns of individual SVM and $\mathrm{NN}$, show the percentage differences between nonSS method with applying the individual SVM and NN-based SS methods, respectively. For the SAR data (Case 1), it was found that the lower accuracies were generated from applying the SVM or $\mathrm{NN}^{-}$ based SS method. However, the applied SVM generated the better results than applied NN for all the cases. The generated best results from the multitemporal SAR and optical data combination (Case 2), $6 \%-8 \%$ of increment from applying SVM and $4 \%-5 \%$ were increased from applying NN. In the optical data (Case 3), the increments of OA (\%) for the SVM were around $8 \%-11 \%$, while for the NN were around $3 \%-9 \%$. While discussing about the supervised SVM and NN classifiers, NN involves the heuristic path, with an extensive experiment preceding theory, whereas the SVM technique is based on the theory. The NN uses the empirical risk minimization, while the SVM uses the structure risk minimization. In addition, the SVM has a simple geometric interpretation and the solution of the SVM is the global and unique. The SVM has also apparently the advantages in avoiding over-fitting which provides the precision of the classification result from the complex and noisy data. From these reasons above, SVM outperforms than the NN.

Among three SS methods, the best classification accuracies in all cases of three major data used were generated from applying the combined SVM and NN-based SS method. It can be seen that the combined SVM and NN-based SS method outper- formed over the individual SVM or NN-based SS methods. Since the SVM and NN classifiers are relatively robust for classification, the pre $^{-}$ identified images were produced based on the individual classifiers. Then, the generating ROI point randomness was performed on the result from the intersection of two pre-identified images. The redundancy is an important factor, which can ensure the accurate identified classes are selected properly or the higher probability for the generation of the correct classes is obtained. In addition, the used SVM and NN classifiers were conducted by using the ENVI software, and ran on an Intel Core 2 Duo $3.16 \mathrm{GHz}$ processor. The computation time for the processes of SVM and NN were quite good, which were 7.31 and 8.20 minutes, respectively. Thus, the combined SVM and NN-based SS method can be used to select accurate ROIs. Consequently, the classification improvement was achieved.

\section{Conclusion}

The framework of multi-temporal SAR and optical data combination with the textural measures for land cover classification based on the Bayesian theory incorporates the SVM; NN; and SVM \& NN-based training sample selecting (SS) methods has been proposed. A three-step classification procedure includes: (1) information fission, by extracting the features of multi-temporal SAR data, optical data, and GLCM textural measures; (2) supervised classification with grayscale values of features from information fission by using Bayesian theory, where the classifier learns the relations between classes and a maximum a posteriori estimation assign the classes; and (3) computation of the final combined membership value function by using logical operators to derive classification result. Then, SS methods were used to generate the accurate and dispersed training samples. Thus, the improved classified results were obtained. The water, woodland, field and built-up classes were studied. The feature integration of three SAR sig- 
nals (i.e., the average backscattering coefficient, the backscattering temporal variability and the longterm coherence) was effective in modelling the series of multi-temporal SAR data. The single source classification was insufficient to carry out the high accuracy and good quality due to the sensor based drawbacks (e.g., the relief displacements and the speckle noise from SAR data; or the cloud cover of optical data). These effects should be accounted prior to implementing the multisource classification. As a result, the classification using multisource information fusion outperformed single source. From numerical tests, the multisource classification (multi-temporal SAR and an optical data combination) with GLCM mean textural measure significantly improved classification accuracy. This was mainly because the appropriate complementary information of different data used ; and the smoothening effect from mean textural increased the performance. In this regard, it was the effective model for both cases, with or without applying the training SS methods. The high quality samples resulting by using the combined SVM and NN-based SS method generated the best classification accuracies in all cases. This framework is general and can be easily extended to identify different land cover classes in any interested areas. In the future development, more classes such as paddy field, crop field, highly urbanized area, and residential area would be distinguished. As a final remark, this classification method shows value as an operational tool for classification problems involving land covers classes.

(受付日2012.5.11, 受理日2012.7.6)

\section{References}

Bruzzone, L. ; Marconcini, M. ; Wegmuller, U. ; Wiesmann, A., 2004. An advanced system for the automatic classification of multi-temporal SAR images. IEEE Trans. Geosci. Remote Sens., 42(6), pp.1321-1334.
Chander, G. ; Markham, B., 2003. Revised Landsat5 TM radiometric calibration procedures and postcalibration dynamic ranges. IEEE Trans. Geosci. Remote Sens., 41, pp.2674-2677.

Cheng, L. ; Gong, J. ; Yang, X. ; Fan, C. ; Han, P., 2008. Robust affine invariant feature extraction for image matching. IEEE Geosci. Remote Sens. Lett., 5(2), pp.246-250.

Cloude, S.R.; Papathanassiou, K.P., 1998. Polarimetric SAR interferometry. IEEE Trans. Geosci. Remote Sens., 36(5), pp.1551-1565.

Duda, R.O. ; Hart, P.E. ; Stork D.G., 2001. Pattern Classification. $2^{\text {nd }}$ ed, New York: Wiley-Interscience Publication.

Hall-Beyer, M., 2007. The GLCM texture tutorial. http://www.fp.ucalgary.ca/mhallbey/tutorial. htm (accessed on 5 Sep. 2010).

Haralick, R.M., 1979. Statistical and structural approaches to texture. Proceedings of the IEEE, 67, pp.786-804.

ITT, 2009. ENVI user's guide, Tech. rep: ITT Visual Information Solutions.

Oliver, C.J.; Quegan, S., 1998. Understanding synthetic aperture radar images. Artech House: Norwood, MA.

Quegan, S. ; Yu, J.J., 2001. Filtering of multichannel SAR images. IEEE Trans. Geosci. Remote Sens., 39(11), pp.2373-2379.

Richards, J.A., 1999. Remote sensing digital image analysis, Springer-Verlag, Berlin, pp.240.

Tso, B. ; Mather, P.M., 2011. Classification methods for remotely sensed data, $2^{\text {nd }} e d$. Taylor and Francis Group, London, pp.283-297.

Tuia, D. ; Ratle, F.; Pacifici, F. ; Kanevski, M.F.; Emery, W.J., 2009. Active learning methods for remote sensing image classification. IEEE Trans. Geosci. Remote Sens., 47(7), pp.2218-2232.

Wu, T.F.; Lin, C.J. ; Weng, R.C., 2004. Probability estimates for multi-class classification by pairwise coupling. Journal of Machine Learning Research. 47, pp.975-1005. 